\title{
Genomic Molecular Signatures Determined Characterization of Mycolicibacterium gossypii sp. nov., a Fast-Growing Mycobacterial Species Isolated From Cotton Field Soil
}

\author{
Ruirui Huang \\ Nanjing Normal University \\ Shenrong Yang \\ Nanjing Normal University \\ Cheng Zhen \\ Nanjing Normal University \\ Xianfeng Ge \\ Nanjing Normal University \\ Xinkai Chen \\ Nanjing Normal University

\section{Zhiqiang Wen} \\ Nanjing Normal University \\ Yanan Li \\ Nanjing Normal University \\ Wenzheng Liu ( $\nabla$ liu.wenzheng@njnu.edu.cn ) \\ Nanjing Normal University https://orcid.org/0000-0003-0710-5748
}

\section{Research Article}

Keywords: Mycolicibacterium, fast-growing, cotton field soil, molecular signatures

Posted Date: May 27th, 2021

DOl: https://doi.org/10.21203/rs.3.rs-560868/v1

License: (c) (i) This work is licensed under a Creative Commons Attribution 4.0 International License. Read Full License

Version of Record: A version of this preprint was published at Antonie van Leeuwenhoek on August 15th, 2021. See the published version at https://doi.org/10.1007/s10482-021-01638-z. 


species isolated from cotton field soil

Authors name: Rui-Rui Huang, Shen-Rong Yang, Cheng Zhen, Xian-Feng Ge, Xin-Kai Chen, Zhi-Qiang Wen, Ya-Nan Li, Wen-Zheng Liu*

Author affiliation: School of Food and Pharmaceutical Engineering, Nanjing Normal University, Nanjing 210023, PR China.

*Correspondence: Wen-Zheng Liu; E-mail: liu.wenzheng@njnu.edu.cn

\begin{abstract}
A Gram-positive, acid-fast and rapidly growing rod, designated $\mathrm{S} 2-37^{\mathrm{T}}$, that could form yellowish colonies was isolated from soil samples collected from cotton cropping field located in the Xinjiang region of China. The draft genome of strain $\mathrm{S} 2-37^{\mathrm{T}}$ was $5.1 \mathrm{Mb}$ in length, with a DNA G+C content of $68.4 \mathrm{~mol} \%$. 16S rRNA-directed phylogenetic analysis referred that strain S2-37 $7^{\mathrm{T}}$ was closely related to bacterial species belonging to the genus Mycolicibacterium and Mycobacterium. Multilocus sequence analysis of three genes (16S rRNA, hsp65 and rpoB) revealed that strain $\mathrm{S} 2-37^{\mathrm{T}}$ shared high sequence similarities with Mycolicibacterium litorale CGMCC $4.5724^{\mathrm{T}}(96.5 \%)$ and Mycobacterium neglectum CECT $8778^{\mathrm{T}}(95.7 \%)$. Digital DNADNA hybridization (dDDH) and the average nucleotide identity (ANI) presented that strainS2$37^{\mathrm{T}}$ displayed the highest values of $39.1 \%(35.7-42.6 \%)$ and $81.28 \%$ with $M$. litorale CGMCC $4.5724^{\mathrm{T}}$, respectively. And characterazition of conserved molecular signatures further confirmed that strain S2-37 $7^{\mathrm{T}}$ could be well classified into the genus Mycolicibacterium. The main fatty acids were identified as $\mathrm{C}_{16: 0}, \mathrm{C}_{18: 0}, \mathrm{C}_{20: 3} \omega 3$ and $\mathrm{C}_{22: 6} \omega 3$. In addition, polar lipids profile was mainly composed of diphosphatidylglycerol, phosphatidylethanolamine and phosphatidylinositol. Results indicated that strain S2-37 ${ }^{\mathrm{T}}$ represented genetically and phenotypically distinct from its closest phylogenetic neighbour, M. litorale CGMCC 4.5724 ${ }^{\mathrm{T}}$. Here, we propose a novel species of the genus Mycolicibacterium: Mycolicibacterium gossypii sp. nov. with the type strain S2-37 $\left(=\mathrm{JCM} 34327^{\mathrm{T}}=\mathrm{CGMCC} 1.18817^{\mathrm{T}}\right)$.
\end{abstract}

Keywords: Mycolicibacterium, fast-growing, cotton field soil, molecular signatures

\title{
Declarations
}

Funding: This work was supported by grants from the Natural Science Foundation of Jiangsu Province (grant no. BK20190703) and The Natural Science Research of the Jiangsu Higher Education Institutions of China (grant no. 19KJB530010).

Conflicts of interest: The authors declare no conflicts of interest.

Availability of data and material: The GenBank/EMBL/DDBJ accession number for the $16 \mathrm{~S}$ rRNA gene sequence of the strain S2-37 ${ }^{\mathrm{T}}$ is MW295419. This Whole Genome Shotgun project has been deposited at DDBJ/ENA/GenBank under the accession JAFEVR000000000. The version described in this paper is version JAFEVR010000000.

Authors' contributions: RRH performed the experiments and finished the draft of the manuscript. RRH, SRY, CZ, XFG and XKC performed strain isolation and phenotypic analyses. RRH and SRY performed genomic analyses. ZQW and YNL assisted to improve the manuscript. WZL designed all the experiments and supervised the manuscript.

Ethical approval: This article does not contain any studies with human participants or animals performed by any of the authors.

Informed consent: All authors agree to publish this work. 
The genus Mycolicibacterium presents the second largest population of Gram-positive, acid-

47 fast and rod-shaped microbes in the family Mycobacteriaceae (Parte et al. 2020). At the time 48 of writing, the genus Mycolicibacterium is composed of 92 recognized species with published names (https://lpsn.dsmz.de) (Parte et al. 2020), which primarily harbors rapid-growing species isolated from diverse range of environments, including river water, marine sediment and soil (Butler et al. 1993; Brown-Elliott et al. 2010; Zhang et al. 2013). There are also relatively high proportion of members in the genus isolated from clinical specimens, showing pathogenic to humans and animals (Shojaei et al. 2000; Brown-Elliott and Wallace 2002). It is well documented that mycobacterial species displayed relatively high diverses in their genomic features at species level (Fedrizzi et al. 2017), which has already remarkably enhanced the difficulty accurately characterizing the taxonomic position of microbial species belonging to this population. Much effort has been devoted to primarily delineate different groups that existes within this meaning fully evolved bacterial branch using well established approaches based on analyses of the $16 \mathrm{~S}$ rRNA gene, $16 \mathrm{~S}-23 \mathrm{~S}$ spacer, and housekeeping gene concatenated multilocus sequences (Roth et al. 1998; Mignard and Flandrois, 2008; Magee and Ward, 2012). However, the reliability of these methods used to well distinguish sub-groups (e.g., slow- and fast-growing species) of mycobacterial species remains of concern. Recently, Gupta et al. (2018) Mycobacterium, Mycolicibacterium, Mycolicibacter, Mycolicibacillus and Mycobacteroides genera. They have identified representative molecular markers in the form of conserved signature indels and proteins, which are uniquely shared by members of the five identified clades. 
In this study, a putative novel species (strain $\mathrm{S} 2-37^{\mathrm{T}}$ ) belonging to mycobacterial species was

70 isolated from soil samples of cotton cropping field of Xinjiang in PR China. Multilocus sequence analysis of three genes (16S rRNA, hsp65 and $r p o B$ ) presented that strain S2-37 ${ }^{\mathrm{T}}$ shared high sequence similarities with microbal species belonging to both the genus Mycolicibacterium and Mycobacterium. In the previous work, conserved molecular signatures (indels and proteins) have been clearly identified as specific markers that could be used to distinguish most members belonging to these two genera confidently (Gupta et al. 2018). Therefore, genome sequence of strain S2-37 was mapped to these documented molecular features specific for each genus, ending up with the conclusion that this strain was taxonomically classified into the genus Mycolicibacterium in combination with following polyphasic approaches.

\section{Materials and methods}

Isolation of the novel strain and cultivation

Strain S2-37 $7^{\mathrm{T}}$ was isolated from a soil sample collected from a cotton cropping field $\left(86^{\circ} 20^{\prime} \mathrm{N}\right.$ $44^{\circ} 62^{\prime} \mathrm{E}$, Xinjiang, China). The isolation procedures were described in the previous report with some modifications (Hopkins et al. 1991). Soil samples (5 g) were firstly naturally dried, then mixed with $100 \mathrm{ml}$ of sterilized water in $250 \mathrm{ml}$ flasks. In order to efficiently elute microbes firmly attached to soil particles, Sample were placed on a shaker with vibration frequency of $160 \mathrm{r} / \mathrm{min}$ at $30^{\circ} \mathrm{C}$ for 30 minutes, followed by homogenization treatment for 1 min using a sonicator (XO-3200DT, Nanjing Xianou laboratory equipment Co., Ltd) with a frequency of $40 \mathrm{kHz}$. Then, $100 \mu \mathrm{l}$ serially diluted samples were plated on Gause's synthetic No.1 agar (G1,

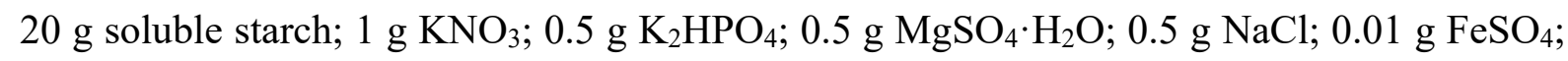
$20 \mathrm{~g}$ Agar; $1000 \mathrm{ml}$ distilled water; $\mathrm{pH}$ 7.2-7.4) for cultivation at $30^{\circ} \mathrm{C}$ in the following 14 days. Bacterial colonies were sub-cultured on G1 agar until pure isolates were achieved. Strain S2-37 $7^{\mathrm{T}}$ was maintained aerobically on $\mathrm{G} 1$ agar at $30^{\circ} \mathrm{C}$, and stored at $-80{ }^{\circ} \mathrm{C}$ in $\mathrm{G} 1$ broth 
supplemented with equal volume of $50 \%(\mathrm{v} / \mathrm{v})$ sterilized glycerol for preservation (Prakash et al. 2013).

Phylogenetic analysis based on 16S rRNA gene and multilocus sequences

Genomic DNA of strain S2-37 was extracted and its 16S rRNA gene was achieved by PCR amplification using universal primers $27 \mathrm{~F}$ and $1492 \mathrm{R}$ as described by Fan et al. (2008), followed by sequence alignment in order to preliminarily locate the taxonomic position of the strain S2-37 ${ }^{\mathrm{T}}$ using the BLAST function embedded in NCBI database (Federhen 2012). GGDC web server (available at http://ggdc.dsmz.de/) was employed for gene phylogenetic and similarity analysis between $16 \mathrm{~S}$ rRNA gene sequences of $\mathrm{S} 2-37^{\mathrm{T}}$ and all published Mycolicibacterium type strains collected from the LPSN database (Parte et al. 2020). Respectively, the phylogenetic trees were reconstructed based on 16S rRNA gene sequences of strains $\mathrm{S} 2-37^{\mathrm{T}}$ and its 22 closely phylogenetic relatives using the neighbor-joining (NJ) (Saitou and Nei 1987), maximum-parsimony (MP) (Sourdis and Nei 1988) and maximumlikelihood (ML) (Steel and Rodrigo 2008) algorithms supported by the software package MEGA 7.0 (Kumar et al. 2016), with Bacillus subtilis NTCC $6051^{\mathrm{T}}$ as the outgroup. The topology of phylogenetic trees was evaluated by performing a bootstrap analysis based on 1000 replications (Felsenstein 1985).

Genomic DNA was extracted from strain S2-37 $7^{\mathrm{T}}$ using Bacterial Genomic DNA Rapid Extraction kit (Cat. No. B518225) supported by Sangon Biotech (Shanghai, China). Library construction, quality control and analysis were performed following the methods described by Zhu et al. (2001). The draft genome of S2-37 was sequenced using Illumina HiSeq 4000 PE150 (Patnaik et al. 2016) at Beijing TSINGKE Bioinformatics Technology Co., Ltd, and assembled using SOAPdenovo (Luo et al. 2012), SPAdes (Bankevich et al. 2012) and Abyss software (Simpson et al. 2009), respectively. The final genome assembly was achieved by integrating three assemblies in CISA software (Lin and Liao 2013). 
It has been reported that $16 \mathrm{~S}$ rRNA-directed phylogenetic analysis could not precisely locate the taxonomic position of all known rapid-growing mycobacteria (Wallace et al. 1993; Brown et al. 1999; Brown-Elliott and Wallace 2002; Wallace et al. 2002), whose members are more closely related to each other. Therefore, phylogenetic analyses were further performed in this study using concatenated sequences composed of the 16S rRNA, hsp 65 and rpoB genes, which were previously proposed as suitable phylogenetic markers for the classification of mycobacteria (Ringuet et al. 1999; Adékambi et al. 2003). The hsp65 and rpoB gene sequences of species were achieved by BLAST against corresponding genomes using the hsp65 (DQ841180) and rpoB (DQ534005) genes of Mycolicibacterium rutilum $\mathrm{JS}^{1} 4^{\mathrm{T}}$ as references. The phylogenetic trees were reconstructed based on the three-gene (16S rRNA, hsp65 and rpoB) concatenated sequences following the same approaches as 16S rRNA-directed phylogenetic trees were built.

\section{Genomic analysis}

Functional categories of the strain $\mathrm{S} 2-37^{\mathrm{T}}$ genome were predicted using the Cluster of Orthologous Group of Proteins (COG) (Tatusov et al. 2003). AntiSMASH was employed to predict biosynthetic gene clusters of strain $\mathrm{S} 2-37^{\mathrm{T}}$ (Blin et al. 2019). Functional gene annotation and metabolic pathway prediction were performed using the Kyoto Encyclopedia of Genes and Genomes (KEGG) database (Kanehisa et al. 2016). The virulence factor database (VFDB) was employed to predict virulence factors of strain S2-37 (Liu et al. 2019). Digital DNA-DNA hybridization ( $\mathrm{dDDH})$ analysis was performed using an automated high-throughput platform for genome-based taxonomy called Type (Strain) Genome Server (TYGS; http://tygs.dsmz.de/) (Meier-Kolthoff et al. 2013), with the genome of strain S2-37 ${ }^{\mathrm{T}}$ as the only query sequence. Additionally, average nucleotide identity (ANI) was calculated with the OrthoANIu algorithm using the server-based software (available at http://www.ezbiocloud.net/tools/ani) (Yoon et al. 2017). 
Divergence analysis of conserved molecular signatures

145

Conserved molecular signatures, including indels (CSIs) and unique proteins (CSPs), specific for the genus Mycolicibacterium and Mycobacterium were directly collected from the work described by Gupta et al. (2018). Conserved protein sequenes of different species with CSIs were achieved by BLASTp searches against the NCBI non-redundant (nr) database (Altschul et al. 2005), and the identified orthologous proteins with a minimum of $50 \%$ in sequence identity were used for divergence analyses. Phylogenetic analyses were performed using the software package MEGA 7.0 after multiple alignments of the sequence data with CLUSTAL W (Kumar et al. 2016). Phylogenetic trees were reconstructed using the neighbor-joining (NJ) algorithms (Saitou and Nei 1987). Partial sequence alignments of a conserved region of orthologous proteins from different species were displayed in same patterns as the previous work did (Gupta et al., 2018). Phylogenetically closely related species to strain S2-37 (Mycolicibacterium litorale CGMCC $4.5724^{\mathrm{T}}$, Mycolicibacterium monacense DSM $44395^{\mathrm{T}}$, Mycobacterium neglectum CECT $8778^{\mathrm{T}}$ and Mycobacterium lehmannii SN 1900 $)$ and randomly chosen species (Mycolicibacterium austroafricanum DSM 44191 , Mycolicibacterium smegmatis NCTC $8159^{\mathrm{T}}$, Mycobacterium asiaticum DSM $44297^{\mathrm{T}}$, Mycobacterium avium $104^{\mathrm{T}}$ and Mycobacterium bohemicum DSM $44277^{\mathrm{T}}$ ) were employed for the divergence analyses. The CSPs profile of strain S2 $-37^{\mathrm{T}}$ was identified using BLASTp searches against the NCBI non-redundant (nr) database, in order to evaluate its phylogenetic relationship with genus Mycolicibacterium and Mycobacterium. Full names will always be used throughout the context for species belonging to the genus Mycobacterium, in order to avoid confusion when refering to species from the genus Mycolicibacterium.

Morphology, physiology, and biochemical analysis

Gram staining was performed using the methods described by Smibert and Krieg (1994) . Acid fastness was conducted using methods described by Berd (1973). Cell morphology was 
determined when grown on Bennett's agar (10 g glucose; $2 \mathrm{~g} \mathrm{~N}-\mathrm{Z}$ amine; $1 \mathrm{~g}$ beef extract; $1 \mathrm{~g}$ yeast extract; $15 \mathrm{~g}$ agar; $1000 \mathrm{ml}$ distilled water; $\mathrm{pH} 7.1-7.5$ ) at $30{ }^{\circ} \mathrm{C}$ for 7 days using a light microscope (OLYMPUS BX43F; Olympus Corporation, Tokyo, Japan) and a cold field emission scanning electron microscope (SEM; Hitachi SU8010, Tokyo, Japan). SEM analysis was performed as described by Koon et al. (2019).

Growth with various $\mathrm{NaCl}$ concentrations $(0-3 \%$ at $0.5 \%$ intervals and $3-7 \%$ at $1 \%$ intervals, $\mathrm{w} / \mathrm{v})$ and at different temperatures $\left(10,18,25,30,37\right.$ and $\left.40,45^{\circ} \mathrm{C}\right)$, was examined by growing the strains on Bennett's medium as the basal medium. Growth at different $\mathrm{pH}$ values $(4.0-10.0$, at intervals of $1.0 \mathrm{pH}$ unit) was examined on Bennett's medium using the buffer system described by $\mathrm{Xu}$ et al. (2005). Catalase activity was determined using $3 \% \mathrm{H}_{2} \mathrm{O}_{2}$, and gas production was identified as a positive reaction. Urease activity, nitrate reduction and tween 80 hydrolysis were determined using methods described by Kent and Kubica (1985). Resistance to antibiotics was determined using impregnated filter-paper discs (Goodfellow and Orchard 1974) containing cefalotin, cefoxitin, amikacin, ciprofloxacin, clarithromycin, doxycycline, tobramycin and sulfamethylisoxazole. Other biochemical properties of strain $\mathrm{S} 2-37^{\mathrm{T}}$ were further tested using the API 20 NE and API ZYM systems (bioMérieux) according to the manufacturer's instructions, and results were summarized in the species description.

\section{Chemotaxonomic characterization}

The polar lipids profile of the strain $\mathrm{S} 2-37^{\mathrm{T}}$ was determined using standard thin-layer chromatographic procedures (Minnikin et al. 1984). In addition, cellular fatty acids were extracted from freeze dried biomass of the strain and were saponified and methylated to produce fatty acid methyl esters (FAMES) following the procedure described by Kuykendall et al. (1988). The FAMES were analyzed by gas chromatography (Agilent 6890 instrument) and the resultant peaks were automatically integrated (Lisec et al. 2006). The fatty acids profile was determined using the standard Microbial Identification (MIDI) System, version 4.5, and 
the Myco 6 database (Sasser 2001).

195

\section{Results and discussion}

Phylogenetic and genomic analyses

Phylogenetic analyses displayed that strain $\mathrm{S} 2-37^{\mathrm{T}}$ showed the highest $16 \mathrm{~S}$ rRNA gene sequence similarity with Mycolicibacterium pyrenivorans DSM $44605^{\mathrm{T}} \quad(98.5 \%)$, Mycobacterium neglectum CECT $8778^{\mathrm{T}}$ (98.5\%), followed by Mycolicibacterium austroafricanum DSM $44191^{\mathrm{T}}(98.3 \%)$ (Table S1). NJ algorithm-directed phylogenetic analysis exhibited that strain $\mathrm{S} 2-37^{\mathrm{T}}$ was located in a clade adjacent to $M$. pyrenivorans DSM $44605^{\mathrm{T}}$, Mycolicibacterium aurum NCTC $10437^{\mathrm{T}}$ and M. austroafricanum DSM $44191^{\mathrm{T}}$, with a low bootstrap support $(<50 \%)$ (Fig. 1a). The phylogenetic distribution pattern could also be recovered by the MP and ML trees (Fig. S1, available in the online version of this article).

Multilocus sequence diretected phylogenetic analyses displayed that strain S2-37 $7^{\mathrm{T}}$ showed higher sequence similarities with Mycolicibacterium litorale CGMCC $4.5724^{\mathrm{T}}(96.5 \%)$ and $M$. austroafricanum DSM $44191^{\mathrm{T}}(96.4 \%)$ as compared to $16 \mathrm{~S}$ rRNA-directed close relatives $M$. pyrenivorans DSM $44605^{\mathrm{T}}(82.5 \%)$ and Mycobacterium neglectum CECT $8778^{\mathrm{T}}(95.7 \%)$ (Table S1), both of which were located in a clade completely separated from where strain S2$37^{\mathrm{T}}$ was as displayed in $\mathrm{NJ}$ algorithm-directed phylogenetic analysis (Fig. 1b). The topology structure was also recovered by the MP and ML trees (Fig. S2, available in the online version of this article).

The assembled genome of S2-37 $7^{\mathrm{T}}$ was $5.9 \mathrm{Mbp}$ with 12 contigs (all $>500 \mathrm{bp}$, with an N50 length of $495170 \mathrm{bp}$ ) and the sequencing coverage was approximately $\times 100$. The total length was 5843440 bp and the $\mathrm{G}+\mathrm{C}$ content was $68.43 \mathrm{~mol} \%$. The results of functional annotation based on the COG database showed that genes involved in lipid transport and metabolism accounted for the largest proportion, except for genes with general function prediction only (Fig. S3). The antiSMASH biosynthetic gene clusters of S2-37 $7^{\mathrm{T}}$ were shown in Supplementary 
table 2, which could provide ideas for guiding the screening of active secondary metabolites. According to the KEGG analysis, the majority of genes were involved in cell metabolism (Fig. S4), and there were some genes classified into the category associated with human diseases (Table S3). This suggested that $\mathrm{S} 2-37^{\mathrm{T}}$ was a potential pathogen of human being, the feature of which was shared by many species belonging to the genus Mycolicibacterium (Gupta et al. 2018). According to the VFDB analysis, strain $\mathrm{S} 2-37^{\mathrm{T}}$ was predicted to be able to produce mycolic acid (see details in Table S4), which was considered as a virulence factor shared by large number of mycobacteria (Tortoli 2003).

Respectively, we then determined that strain $\mathrm{S} 2-37^{\mathrm{T}}$ presented $\mathrm{dDDH}$ values (average and confidence intervals in parentheses) of 39.1\% (35.7-42.6\%) and 34.9\% (35.0-38.4\%) with $M$. litorale CGMCC $4.5724^{\mathrm{T}}$ and M. monacense DSM $44395^{\mathrm{T}}$, showing much lower $\mathrm{dDDH}$ values of $23.0 \%(19.7-26.6 \%)$ and $20.5 \%(27.3-24.1 \%)$ with $M$. austroafricanum DSM $44191^{\mathrm{T}}$ and Mycobacterium neglectum CECT $8778^{\mathrm{T}}$. This provided a sound evidence supporting the result achieved from the phylogenetic tree based on multilocus sequences of $16 \mathrm{~S}$ rRNA, hsp 65 and $r p o B$ genes, suggesting closely phylogenetic relationships of strain $\mathrm{S} 2-37^{\mathrm{T}}$ with $M$. litorale CGMCC $4.5724^{\mathrm{T}}$ and $M$. monacense DSM $44395^{\mathrm{T}}$. The ANI values between strain $\mathrm{S} 2-37^{\mathrm{T}}$ and M. litorale CGMCC $4.5724^{\mathrm{T}}$ and M. monacense DSM $44395^{\mathrm{T}}$ were $81.28 \%$ and $81.09 \%$, respectively. Overall, all calculated values were below the suggested threshold for the delineation of a novel species (Chun et al. 2018).

Divergence analysis of conserved molecular signatures

Respectively, four (LacI family transcriptional regulator, cyclase, CDP-alcohol phosphatidyltransferase and phosphatidylserine synthase) and two (UPF0182 family protein and 23S rRNA (guanosine(2251)-2'-O)-methyltransferase RlmB) conserved proteins with CSIs specific for most members of the genus Mycolicibacterium and Mycobacterium were employed for the divergence analysis. Phylogenetic analyses based on whole sequences of four 
conserved proteins (LacI family transcriptional regulator, CDP-alcohol

phosphatidyltransferase, UPF0182 family protein and RlmB) indicated that strain $\mathrm{S} 2-37^{\mathrm{T}}$ was more closely related to members from the genus Mycolicibacterium as compared to those from the genus Mycobacterium. And in the partial sequence alignments of these four proteins, the amino acid insertion partterns of strain $\mathrm{S} 2-37^{\mathrm{T}}$ were consistent with the molecular signatures (Fig. 2; Fig. S5b, d, e), which were specific for most members within the genus Mycolicibacterium identified by Gupta et al. (2018). However, conserved regions of protein sequences (cyclase and phosphatidylserine synthase) did not give a clear clue where strain S2$37^{\mathrm{T}}$ could be taxonomically positioned (Fig. S5a, c). The CSPs profile of strain S2-37 ${ }^{\mathrm{T}}$ was summarized in table 1. It was clearly shown that strain S2-37 $7^{\mathrm{T}}$ possessed some identified CSPs specific for members of the genus Mycocilibacterium, but none for members of the genus Mycobacterium and other slow growers of mycobacterial species. Thus, we concluded that strain S2-37 $7^{\mathrm{T}}$ represented a novel bacterial species in the genus Mycolicibacterium.

Table 1. Similarity of conserved signature proteins (CSPs) between strain S2-37 ${ }^{\mathrm{T}}$ and members of the genus Mycocilibacterium, slow growers of mycobacterial species and the genus Mycobacterium.

\begin{tabular}{ccccc}
\hline Gene or protein & $\begin{array}{c}\text { Accession number of } \\
\text { reference protein }\end{array}$ & $\begin{array}{c}\text { Sequence } \\
\text { coverage (\%) }\end{array}$ & $\begin{array}{c}\text { Sequence } \\
\text { identity (\%) }\end{array}$ & Specificity \\
\hline Hypothetical protein & WP_048630777.1 & 96 & 71.59 & \\
Hypothetical protein & WP_048632025.1 & - & - & \\
Hypothetical protein & WP_048632497.1 & 56 & 57.78 & \\
Hypothetical protein & WP_048634851.1 & - & - & \\
Hypothetical protein & WP_048633467.1 & 49 & 47.47 & Mycocilibacterium \\
Hypothetical protein & WP_048633322.1 & 96 & 40.94 & \\
Hypothetical protein & WP_048631132.1 & 48 & 29.07 & \\
Hypothetical protein & WP_048634509.1 & 70 & 46.03 & \\
Hypothetical protein & WP_048630657.1 & 41 & 47.62 & \\
Hypothetical protein & WP_048632441.1 & 60 & 48.77 & \\
\hline PPE Family protein & YP_177721.1 & 6 & 38.24 & Slow-Growers of \\
\hline
\end{tabular}




\begin{tabular}{|c|c|c|c|c|}
\hline \multirow[b]{2}{*}{ PE Family protein PE36 } & \multirow[b]{2}{*}{ YP_178025.1 } & \multirow[b]{2}{*}{-} & \multirow[b]{2}{*}{-} & \multirow[b]{2}{*}{ mycobacterial } \\
\hline & & & & \\
\hline PE Family protein & WP_011725130.1 & - & - & species \\
\hline MAP_RS07685 & WP_003874405.1 & - & - & \\
\hline Histone-like protein HNS & NP_218639.1 & - & - & \\
\hline Rv4010 & YP_004837050.1 & - & - & Mycobacterium \\
\hline Membrane protein & NP_217322.1 & - & - & \\
\hline
\end{tabular}

260

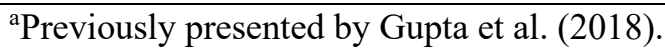

The symbol: -, not detected.

Intriguingly, we observed that Mycobacterium neglectum $\mathrm{CECT} 8778^{\mathrm{T}}$ and Mycobacterium lehmannii SN $1900^{\mathrm{T}}$ displayed similar CSIs patterns with members of the genus Mycolicibacterium. It has been reported that these two species were capable of forming colonies within 7 days (Nouioui et al. 2017, 2018), and their most phylogenetically closely related species (e.g., Mycobacterium aurum, Mycobacterium mageritense and Mycobacterium vanbaalenii) have been reclassified into the genus Mycolicibacterium (Gupta et al. 2018). Therefore, we suggested that Mycobacterium neglectum and Mycobacterium lehmannii should be modified to Mycolicibacterium neglectum and Mycolicibacterium lehmannii, respectively. Morphology, physiology, and biochemical analysis

Strain $\mathrm{S} 2-37^{\mathrm{T}}$ showed more robust growth on Bennett's agar as compared to G1 and R2A agar. It could form round, yellowish colonies stably on Bennett's agar. SEM observation revealed that strain $\mathrm{S} 2-37^{\mathrm{T}}$ is rod-shaped, approximately $1.0-1.5 \mu \mathrm{m}$ in length and $0.4 \mu \mathrm{m}$ in diameter (Fig. 3). Positive for catalase activity and negative for Tween 80 hydrolysis, other results achieved from strains $\mathrm{S} 2-37^{\mathrm{T}}, M$. litorale CGMCC $4.5724^{\mathrm{T}}$ and M. monacense DSM $44395^{\mathrm{T}}$, were summarized in Table 2. All of these tests were carried out in duplicate using the standard inoculum.

Table 2. Differential characteristics between strain $\mathrm{S} 2-37^{\mathrm{T}}$ and closely related species in the genus Mycolicibacterium.

\begin{tabular}{llll}
\hline Characteristic & 1 & 2 & 3 \\
\hline Growth at $\mathrm{pH} 4.0$ & + & + & +
\end{tabular}




$\begin{array}{llll}\text { Growth with } 4 \% \mathrm{NaCl} & - & + & + \\ \text { Temperature range }\left({ }^{\circ} \mathrm{C}\right) & 18-40 & 25-45 & 25-45 \\ \text { Catalase } & + & + & + \\ \text { Urease } & - & + & + \\ \text { Nitrate reduction } & - & + & - \\ \text { Tween } 80 \text { hydrolysis } & - & + & + \\ \text { Antibiotics resistance: } & & & \\ \text { Cefalotin } & + & - & - \\ \text { Cefoxitin } & + & - & - \\ \text { Amikacin } & - & - & - \\ \text { Ciprofloxacin } & - & - & - \\ \text { Clarithromycin } & - & + & + \\ \text { Doxycycline } & - & - & - \\ \text { Tobramycin } & - & - & - \\ \text { Sulfamethylisoxazole } & - & - & -\end{array}$

280 Strains: 1 , S2-37 ${ }^{\mathrm{T}} ; 2$, M. litorale CGMCC $4.5724^{\mathrm{T}} ; 3$, M. monacense DSM $44395^{\mathrm{T}}$. All data was from this 281 study. The symbols: +, Positive; -, negative.

282 Chemotaxonomic characterization

283 The major polar lipids of strain $\mathrm{S} 2-37^{\mathrm{T}}$ were identified as diphosphatidylglycerol, 284 phosphatidylethanolamine and phosphatidylinositol (Fig. S6). The major fatty acids ( $>10 \%)$ of strain $\mathrm{S} 2-37^{\mathrm{T}}$ were composed of $\mathrm{C}_{16: 0}, \mathrm{C}_{18: 0}, \mathrm{C}_{20: 3} \omega 3$ and $\mathrm{C}_{22: 6} \omega 3$, of which the last two types of fatty acids were not detected or only traced in small amounts $(<1 \%)$ in $M$. litorale CGMCC 4.5724 ${ }^{\mathrm{T}}$ and M. monacense DSM 44395 ${ }^{\mathrm{T}}$ (Reischl et al. 2006; Zhang et al. 2012). In conclusion, the phenotypic, chemotaxonomic and phylogenetic data supports the delineation of strain $\mathrm{S} 2-37^{\mathrm{T}}$ as a novel species of the genus Mycolicibacterium. We propose the name Mycolicibacterium gossypii sp. nov. for the species.

Description of Mycolicibacterium gossypii sp.nov.

Mycolicibacterium gossypii (gos.sy'pi.i. N.L. gen. n. gossypii of the cotton genus Gossypium). Cells are aerobic, Gram-stain-positive, acid-fast, non-spore-forming and short rods. It could form smooth, yellowish colonies on Bennett's agar within 7 days at $30{ }^{\circ} \mathrm{C}$. Cells are approximately $0.4 \mu \mathrm{m}$ in diameter and 1.0-1.5 $\mu \mathrm{m}$ long. Positive for catalase activity and 
negative for Tween 80 hydrolysis. In API 20NE tests, arginine dihydrolase activitie is positive. Negative for nitrate reduction, indole production, $\beta$-galactosidase, $\beta$-glucosidase, gelatinase and urease activities, as well as fermentation of D-glucose. In addition, results are negative for assimilation of D-glucose, L-arabinose, D-mannitiol, maltose, gluconate, N-acetylglucosamine, adipic acid, malic acid, capric acid and phenylacetic acid, but positive for citrate acid. In API ZYM tests, alkaline phosphatase, esterase (C4), esterase lipase (C8), leucine arylamidase, valine arylamidase, cystine arylamidase, acid phosphatase, naphthol-AS-BIphosphohydrolase, $\alpha$-glucosidase activities are positive. Negative for lipase (C14), trypsin, $\alpha$ chymotrypsin, $\alpha$-galactosidase, $\beta$-galactosidase, $\beta$-glucuronidase, $N$-acetyl- $\beta$-glucosaminidase, $\alpha$-mannosidase and $\alpha$-rucosidase activities. Susceptible to amikacin, ciprofloxacin, clarithromycin, doxycycline, tobramycin and sulfamethylisoxazole, but resistant to cefalotin and cefoxitin. The major fatty acids $(>10 \%)$ are $\mathrm{C}_{16: 0}, \mathrm{C}_{18: 0}, \mathrm{C}_{20: 3} \omega 3$ and $\mathrm{C}_{22: 6} \omega 3$. The polar lipids profile is mainly composed of diphosphatidylglycerol, phosphatidylethanolamine and phosphatidylinositol. The genome size of strain $\mathrm{S} 2-37^{\mathrm{T}}$ is $5.9 \mathrm{Mbp}$ and the DNA G+C content of the type strain is $68.4 \mathrm{~mol} \%$. The GenBank/EMBL/DDBJ accession numbers for the $16 \mathrm{~S}$ rRNA sequence is MW295419. This Whole Genome Shotgun project has been deposited at GenBank/EMBL/DDBJ under the accession number JAFEVR000000000. The version described in this paper is version JAFEVR010000000.

The type strain, $\mathrm{S} 2-37^{\mathrm{T}}\left(=\mathrm{JCM} 34327^{\mathrm{T}}=\mathrm{CGMCC} 1.18817^{\mathrm{T}}\right)$, was isolated from cotton field soil in Xinjiang, PR China.

\section{Acknowledgement}

The authors thank Dr. Zhi-Dong Zhang from Xinjiang Academy of Agricultural Sciences of China for his assistance with sampling. 
321 Fig. 1. Phylogenetic trees reconstructed by the neighbour-joining method based on 16S rRNA 322 (a) and multilocus gene (16S rRNA, hsp65 and rpoB) (b) sequences, which show the 323 phylogenetic relationships between strain S2-37 and its closely related species. Bootstrap percentages (based on 1000 replications) above 50\% are shown at the nodes. The GenBank accession numbers for the 16S rRNA gene and genomic sequences are shown in parentheses. Bacillus subtilis subsp. subtilis JCM $1465^{\mathrm{T}}$ was employed as the outgroup. Filled circles indicate that the corresponding nodes are also recovered in trees reconstructed by the ML and MP algorithms. Bar, 0.02 (a) and 0.05 (b) substitutions per nucleotide position.

Fig. 2. The phylogenetic tree displayed in the left column is reconstructed by the neighbourjoining method based on the whole sequences of LacI family transcriptional regulator from tested members of the genus Mycocilibacterium and Mycobacterium, conserved region alignment of which is displayed in the right colume. Sequence information for additional CSIs is shown in Supplementary Figure 5.

Fig. 3. Scanning electron micrograph exhibiting cell morphology of strain $\mathrm{S} 2-37^{\mathrm{T}}$. The cells used for investigation were cultured on Bennett's agar at $30{ }^{\circ} \mathrm{C}$ for $4 \mathrm{~d}$. Magnification, $\times 20.0$ k. Scale bar, $2.0 \mu \mathrm{m}$. 


\section{Captions of supplementary figures and tables}

339

Fig. S1. Phylogenetic trees reconstructed by the maximum-parsimony (a) and maximumlikelihood (b) methods based on 16S rRNA gene sequences. Bootstrap values with more than $50 \%$ are shown on the nodes as percentages of 1,000 replicates. The GenBank accession numbers for 16S rRNA gene sequences are shown in parentheses. Bacillus subtilis subsp. subtilis JCM $1465^{\mathrm{T}}$ was employed as the outgroup. Bar, 20 (a) and 0.02 (b) substitutions per nucleotide position.

Fig. S2. Phylogenetic trees reconstructed by the maximum-parsimony (a) and maximumlikelihood (b) methods based on the multilocus gene (16S rRNA, hsp65 and rpoB) sequences. Bootstrap values with more than $50 \%$ are shown on the nodes as percentages of 1,000 replicates. The GenBank accession numbers for the 16S rRNA gene and genomic sequences are shown in parentheses. Bacillus subtilis subsp. subtilis JCM $1465^{\mathrm{T}}$ was employed as the outgroup. Bar, 100 (a) and 0.05 (b) substitutions per nucleotide position.

Fig. S3. Predicted functional categories of strain S2-37 $7^{\mathrm{T}}$ based on COG orthologous groups. Fig. S4. Predicted metabolic pathway of strain S2-37 $7^{\mathrm{T}}$ genome using KEGG database.

Fig. S5. Phylogenetic trees displayed in the left column are reconstructed by the neighbourjoining method based on the whole sequences of cyclase (a), CDP-alcohol phosphatidyltransferase (b), phosphatidylserine synthase (c), UPF0182 family protein (d) and $\mathrm{R} \operatorname{lmB}$ (e) from tested members of the genus Mycocilibacterium and Mycobacterium, conserved region alignments of which are displayed in the right column.

Fig. S6. Polar lipids profile of strain $\mathrm{S} 2-37^{\mathrm{T}}$ following two-dimensional TLC and detection with molybdatophosphoric acid. The solvent system was composed of chloroform-methanolwater (65:25:4, by vol.) for the first development and of chloroform-methanol-glacial acetic acid-water (80:12:15:4, by vol.) for the second development. DPG, diphosphatidylglycerol; PE, phosphatidylethanolamine; PI, Phosphatidylinositol. 
Table S1. Sequence similarities between strain S2-37 and closely related species in the genus

\section{Mycolicibacterium and Mycobacterium.}

Table S2. Biosynthetic gene clusters in the draft genome of strain $\mathrm{S} 2-37^{\mathrm{T}}$ predicted by antiSMASH.

Table S3. The predicted pathways of strain $\mathrm{S} 2-37^{\mathrm{T}}$ genome classified into the category of human diseases.

Table S4. The predicted virulence factors of strain S2-37 $7^{\mathrm{T}}$ using VFDB database.

\section{References}

Adékambi T, Colson P, Drancourt M (2003) RpoB-based identification of nonpigmented and latepigmenting rapidly growing Mycobacteria. J Clin Microbiol 41(12):5699-5708. https://doi.org/10.1128/JCM.41.12.5699-5708.2003

Altschul S, Wootton J, Gertz E, Agarwala R, Morgulis A, Schäffer A, Yu Y (2005) Protein database searches using compositionally adjusted substitution matrices. FEBS Journal 272:5101-5109. https://doi.org/10.1111/j.1742-4658.2005.04945.x

Bankevich A, Nurk S, Antipov D, Gurevich AA, Dvorkin M, Kulikov A, Lesin V, Nikolenko S, Pham S, Prjibelski A, Pyshkin A, Sirotkin A, Vyahhi N, Tesler G, Alekseyev M, Pevzner P (2012) SPAdes: A new genome assembly algorithm and its applications to single-cell sequencing. J Comput Biol 19(5):455-477. https://doi.org/10.1089/cmb.2012.0021

Berd D (1973) Laboratory identification of clinically important aerobic actinomycetes. Appl Microbiol 25(4):665-681. https://doi.org/10.1128/aem.25.4.665-681.1973

Blin K, Shaw S, Steinke K, Villebro R, Ziemert N, Lee S, Medema M, Weber T (2019) AntiSMASH 5.0: Updates to the secondary metabolite genome mining pipeline. Nucleic Acids Res 47:81-87. https://doi.org/10.1093/nar/gkz310

Brown BA, Springer B, Steingrube VA, Wilson RW, Pfyffer GE, Garcia M, Menendez M, RodriguezSalgado B, Jost K, Chiu S, Onyi G, Böttger E, Wallace R (1999) Mycobacterium wolinskyi sp. nov. and Mycobacterium goodii sp. nov., two new rapidly growing species related to Mycobacterium smegmatis and associated with human wound infections: A cooperative study from the International Working Group on Mycobacterial Taxonomy. Int J Syst Bacteriol 49(4):1493-1511. https://doi.org/10.1099/00207713-49-4-1493

Brown-Elliott BA, Wallace RJ (2002) Clinical and taxonomic status of pathogenic nonpigmented or latepigmenting rapidly growing mycobacteria. Clin Microbiol Rev 15:716-746. https://doi.org/10.1128/CMR.15.4.716-746.2002

Brown-Elliott BA, Wallace RJ, Petti CA, Mann LB, McGlasson M, Chihara S, Smith G, Painter P, Hail D, Wilson R, Simmon K (2010) Mycobacterium neoaurum and Mycobacterium bacteremicum sp. nov. as causes of mycobacteremia. J Clin Microbiol 48(12):4377-4385. https://doi.org/10.1128/JCM.00853-10

Butler WR, O’Connor SP, Yakrus MA, Smithwick RW, Plikaytis B, Moss C, Floyd M, Woodley C, Kilburn J, Vadney F, Gross W (1993) Mycobacterium celatum sp. nov. Int J Syst Bacteriol 43(3):539548. https://doi.org/10.1099/00207713-43-3-539

Chun J, Oren A, Ventosa A, Christensen H, Arahal DR, da Costa M, Rooney A, Yi H, Xu X, De Meyer S, Trujillo M (2018) Proposed minimal standards for the use of genome data for the taxonomy of prokaryotes. Int J Syst Evol Microbiol 68:461-466. https://doi.org/10.1099/ijsem.0.002516

Fan H, Su C, Wang Y, Yao J, Zhao K, Wang Y, Wang G (2008) Sedimentary arsenite-oxidizing and arsenate-reducing bacteria associated with high arsenic groundwater from Shanyin, Northwestern China. J Appl Microbiol 105(2):529-539. https://doi.org/10.1111/j.1365-2672.2008.03790.x

Federhen S (2012) The NCBI taxonomy database. Nucleic Acids Res 40:136-143. 
https://doi.org/10.1093/nar/gkr1178

Fedrizzi T, Meehan C, Grottola A, Giacobazzi E, Fregni Serpini G, Tagliazucchi S, Fabio A, Bettua C, Bertorelli R, De Sanctis V, Rumpianesi F, Pecorari M, Jousson O, Tortoli E, Segata N (2017) Genomic characterization of Nontuberculous Mycobacteria. Sci Rep 7:45258. https://doi.org/10.1038/srep45258

Felsenstein J (1985) Confidence limits on phylogenies: An approach using the bootstrap. Evolution. 39(4):783-791. https://doi.org/10.2307/2408678

Goodfellow M, Orchard VA (1974) Antibiotic sensitivity of some nocardioform bacteria and its value as a criterion for taxonomy. J Gen Microbiol 83(2):375-387. https://doi.org/10.1099/00221287-83-2-375

Gupta RS, Lo B, Son J (2018) Phylogenomics and comparative genomic studies robustly support division of the genus Mycobacterium into an emended genus Mycobacterium and four novel genera. Front Microbiol 9. https://doi.org/10.3389/fmicb.2018.00067

Hopkins DW, Macnaughton SJ, O’Donnell AG (1991) A dispersion and differential centrifugation technique for representatively sampling microorganisms from soil. Soil Biol Biochem 23(3):217-225. https://doi.org/10.1016/0038-0717(91)90055-O

Kanehisa M, Sato Y, Morishima K (2016) BlastKOALA and GhostKOALA: KEGG tools for functional characterization of genome and metagenome sequences. J Mol Biol 428(4):726-731. https://doi.org/10.1016/j.jmb.2015.11.006

Koon MA, Almohammed Ali K, Speaker RM, McGrath JP, Linton EW, Steinhilb M (2019) Preparation of prokaryotic and eukaryotic organisms using chemical drying for morphological analysis in scanning electron microscopy (SEM). J Vis Exp 143:e58761. https://doi.org/10.3791/58761

Kubica G, Kent K (1985) Public health mycobacteriology: A guide for the level III laboratory. Centers for Disease Control, U.S. Department of Health and Human Services, Atlanta, GA, Washington, D.C.

Kumar S, Stecher G, Tamura K (2016) MEGA7: Molecular evolutionary genetics analysis version 7.0 for bigger datasets. Mol Biol Evol 33(7):1870-1874. https://doi.org/10.1093/molbev/msw054

Kuykendall LD, Roy MA, O’Neill JJ, Devine TE (1988) Fatty acids, antibiotic resistance, and deoxyribonucleic acid homology groups of Bradyrhizobium japonicum. Int J Syst Bacteriol 38(4):358361. https://doi.org/10.1099/00207713-38-4-358

Lin SH, Liao YC (2013) CISA: Contig integrator for sequence assembly of bacterial genomes. PLoS One. 8(3):e60843. https://doi.org/10.1371/journal.pone.0060843

Lisec J, Schauer N, Kopka J, Wilmitzer L, Fernie AR (2006) Gas chromatography mass spectrometrybased metabolite profiling in plants. Nat Protoc 1(1):387-396. https://doi.org/10.1038/nprot.2006.59

Liu B, Zheng DD, Jin Q, Chen LH, Yang J (2019) VFDB 2019: A comparative pathogenomic platform with an interactive web interface. Nucleic Acids Res 47:687-692. http://scihub.ren/10.1093/nar/gky1080

Luo R, Liu B, Xie Y, Li Z, Huang W, Yuan J, He G, Chen Y, Pan Q, Liu Y, Tang J, Wu G, Zhang H, Shi Y, Liu Y, Yu C, Wang B, Lu Y, Han C, Cheung D, Yiu S, Peng S, Xiaoqian Z, Liu G, Liao X, Li Y, Yang H, Wang J, Lam T, Wang J (2012) SOAPdenovo2: An empirically improved memoryefficient short-read de novo assembler. GigaScience. 1(1):18. https://doi.org/10.1186/2047-217X-1-18

Magee G, Ward A (2012) Genus I. Mycobacterium Lehmann and Neumann 1896, 363AL. In: Goodfellow M, Kampfer P, Busse HJ, Trujillo ME, Suzuki K, Ludwig W, and Whitman W (eds) Bergey's Manual of Systematic Bacteriology, Vol. 5, Actinobacteria. Springer, New York, pp 312-375.

Meier-Kolthoff JP, Auch AF, Klenk HP, Göker M (2013) Genome sequence-based species delimitation with confidence intervals and improved distance functions. BMC Bioinformatics. 14:60. https://doi.org/10.1186/1471-2105-14-60

Mignard S, Flandrois J (2008). A seven-gene, multilocus, genus-wide approach to the phylogeny of mycobacteria using supertrees. Int J Syst Evol Microbiol 58(6):1432-1441. https://doi.org/10.1099/ijs.0.65658-0

Minnikin DE, O’Donnell AG, Goodfellow M, Alderson G, Athalye M, Schaal A, Parlett J (1984) An integrated procedure for the extraction of bacterial isoprenoid quinones and polar lipids. $\mathrm{J}$ Microbiol Methods 2(5):233-241. https://doi.org/10.1016/0167-7012(84)90018-6

Nouioui I, Carro L, García-López M, Meier-Kolthoff J, Woyke T, Kyrpides N, Pukall R, Klenk H, Goodfellow M, Göker M (2018) Genome-based taxonomic classification of the phylum actinobacteria. Front Microbiol 9. https://doi.org/10.3389/fmicb.2018.02007

Nouioui I, Sangal V, Carro L, Teramoto K, Jando M, Montero-Calasanz MDC, Igual JM, Sutcliffe I, Goodfellow M, Klenk HP (2017) Two novel species of rapidly growing mycobacteria: Mycobacterium lehmannii sp. nov. and Mycobacterium neumannii sp. nov. Int J Syst Evol Microbiol 67(12):4948-4955. 
Parte A, Carbasse J, Meier-Kolthoff J, Reimer L, Göker M (2020) List of Prokaryotic names with Standing in Nomenclature (LPSN) moves to the DSMZ. Int J Syst Evol Microbiol 70(11):5607-5612. https://doi.org/10.1099/ijsem.0.004332

Patnaik BB, Park SY, Kang SW, Hwang HJ, Wang TH, Park E, Chung J, Song D, Kim C, Kim S, Lee J, Jeong H, Park H, Han Y, Lee Y (2016) Transcriptome profile of the Asian Giant Hornet (Vespa mandarinia) using Illumina HiSeq 4000 sequencing: De novo assembly, functional annotation, and discovery of SSR markers. Int J Genomics 2016:4169587. https://doi.org/10.1155/2016/4169587

Prakash O, Nimonkar Y, Shouche YS (2013) Practice and prospects of microbial preservation. FEMS Microbiol Lett 339:1-9. https://doi.org/10.1111/1574-6968.12034

Reischl U, Melzl H, Kroppendstedt RM, Miethke T, Naumann L, Mariottini A, Mazzarelli G, Tortoli E (2006) Mycobacterium monacense sp. nov. Int J Syst Evol Microbiol 56:2575-2578. https://doi.org/10.1099/ijs.0.64527-0

Ringuet H, Akoua-Koffi C, Honore S, Varnerot A, Vincent V, Berche P, Gaillard J, Pierre-Audigier C (1999) Hsp65 sequencing for identification of rapidly growing mycobacteria. J Clin Microbiol 37(3):852-857. https://doi.org/10.1128/jcm.37.3.852-857.1999

Roth A, Fischer M, Hamid M, Michalke S, Ludwig W, Mauch H (1998) Differentiation of phylogenetically related slowly growing mycobacteria based on 16S-23S rRNA gene internal transcribed spacer sequences. J Clin Microbiol 36(1):139-147. https://doi.org/10.1128/JCM.36.1.139-147.1998

Saitou N, Nei M (1987) The neighbor-joining method: A new method for reconstructing phylogenetic trees. Mol Biol Evol 4(4):406-425. https://doi.org/10.1093/oxfordjournals.molbev.a040454

Sasser M (2001) Identification of bacteria by gas chromatography of cellular fatty acids. Tech Note 101,16.

Shojaei H, Magee JG, Freeman R, Yates M, Horadagoda NU, Goodfellow M (2000) Mycobacterium elephantis sp. nov., a rapidly growing non-chromogenic Mycobacterium isolated from an elephant. Int $\mathbf{J}$ Syst Evol Microbiol 50(5):1817-1820. https://doi.org/10.1099/00207713-50-5-1817

Simpson JT, Wong K, Jackman SD, Schein JE, Jones SJM, Birol I (2009) ABySS: A parallel assembler for short read sequence data. Genome Res 19(6):1117-1123. https://doi.org/10.1101/gr.089532.108

Smibert RM, Krieg NR (1994) Phenotypic characterization. In: Gerhardt P, Murray RGE, Wood WA, Krieg NR (eds) Methods for general and molecular bacteriology. American Society for Microbiology, Washington, pp 607-654.

Sourdis J, Nei M (1988) Relative efficiencies of the maximum parsimony and distance-matrix methods in obtaining the correct phylogenetic tree. Mol Biol Evol 11(2):261-277. https://doi.org/10.1093/oxfordjournals.molbev.a040497

Steel M, Rodrigo A (2008) Maximum likelihood supertrees. Syst Biol 57(2):243-250. https://doi.org/10.1080/10635150802033014

Tatusov R, Fedorova N, Jackson J, Jacobs A, Kiryutin B, Koonin E, Krylov D, Mazumder R, Smirnov S, Nikolskaya A, Rao B, Mekhedov S, Sverlov A, Vasudevan S, Wolf Y, Yin J, Natale D (2003) The COG database: An updated version includes eukaryotes. BMC Bioinformatics 4(4):1-14. https://doi.org/10.1186/1471-2105-4-41

Tortoli E (2003) Impact of genotypic studies on mycobacterial taxonomy: The new mycobacteria of the 1990s. Clin Microbiol Rev 16:319-354. http://sci-hub.ren/10.1128/CMR.16.2.319-354.2003

Wallace RJ, Brown-Elliott BA, Hall L, Roberts G, Wilson RW, Mann L, Crist C, Chiu S, Dunlap R, Garcia M, Bagwell J, Jost K (2002) Clinical and laboratory features of Mycobacterium mageritense. J Clin Microbiol 40(8):2930-2935. https://doi.org/10.1128/JCM.40.8.2930-2935.2002

Wallace RJ, Silcox VA, Tsukamura M, Brown BA, Kilburn JO, Butler W, Ony G (1993) Clinical significance, biochemical features, and susceptibility patterns of sporadic isolates of the Mycobacterium chelonae-like organism. J Clin Microbiol 31(12):3231-3239. https://doi.org/10.1128/jcm.31.12.32313239.1993

Xu P, Li W, Tang S, Zhang Y, Chen G, Chen H, Xu L, Jiang C (2005) Naxibacter alkalitolerans gen. nov., sp. nov., a novel member of the family 'Oxalobacteraceae' isolated from China. Int J Syst Evol Microbiol 55:1149-1153. https://doi.org/10.1099/ijs.0.63407-0

Yoon S, Ha S, Lim J, Kwon S, Chun J (2017) A large-scale evaluation of algorithms to calculate average nucleotide identity. ANTON LEEUW INT J G 110(10):1281-1286. https://doi.org/10.1007/s10482-0170844-4

Zhang D, Chen X, Zhang X, Zhi X, Yao J, Jiang Y, Xiong Z, Li W (2013) Mycobacterium sediminis sp. nov. and Mycobacterium arabiense sp. nov., two rapidly growing members of the genus Mycobacterium. Int J Syst Evol Microbiol 63:4081-4086. https://doi.org/10.1099/ijs.0.050567-0 
Zhang Y, Zhang J, Fang C, Pang H, Fan J (2012) Mycobacterium litorale sp. nov., a rapidly growing mycobacterium from soil. Int J Syst Evol Microbiol 62:1204-1207. https://doi.org/10.1099/ijs.0.0334490

Zhu YY, Machleder EM, Chenchik A, Li R, Siebert PD (2001) Reverse transcriptase template switching: A SMART ${ }^{\mathrm{TM}}$ approach for full-length cDNA library construction. BioTechniques 30:892-897. https://doi.org/10.2144/01304pf02 


\section{Figures}

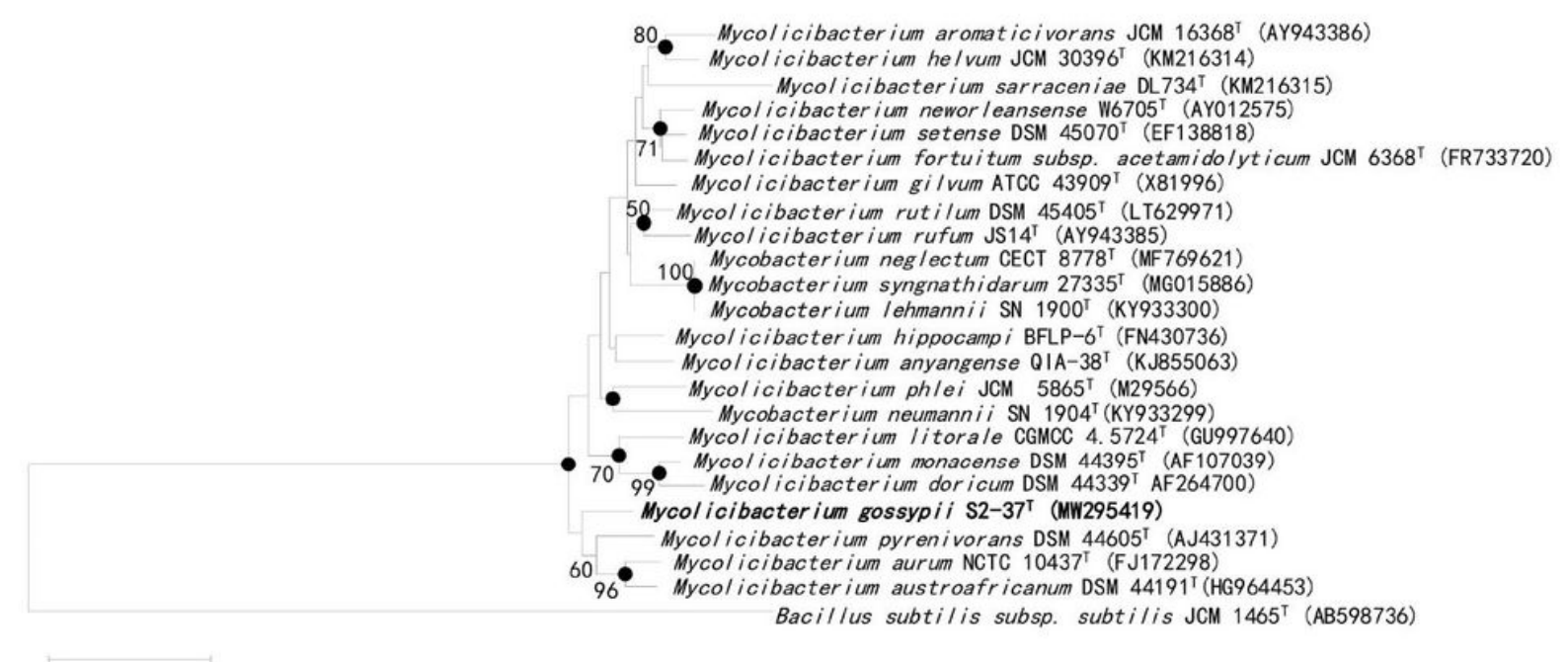

0.020

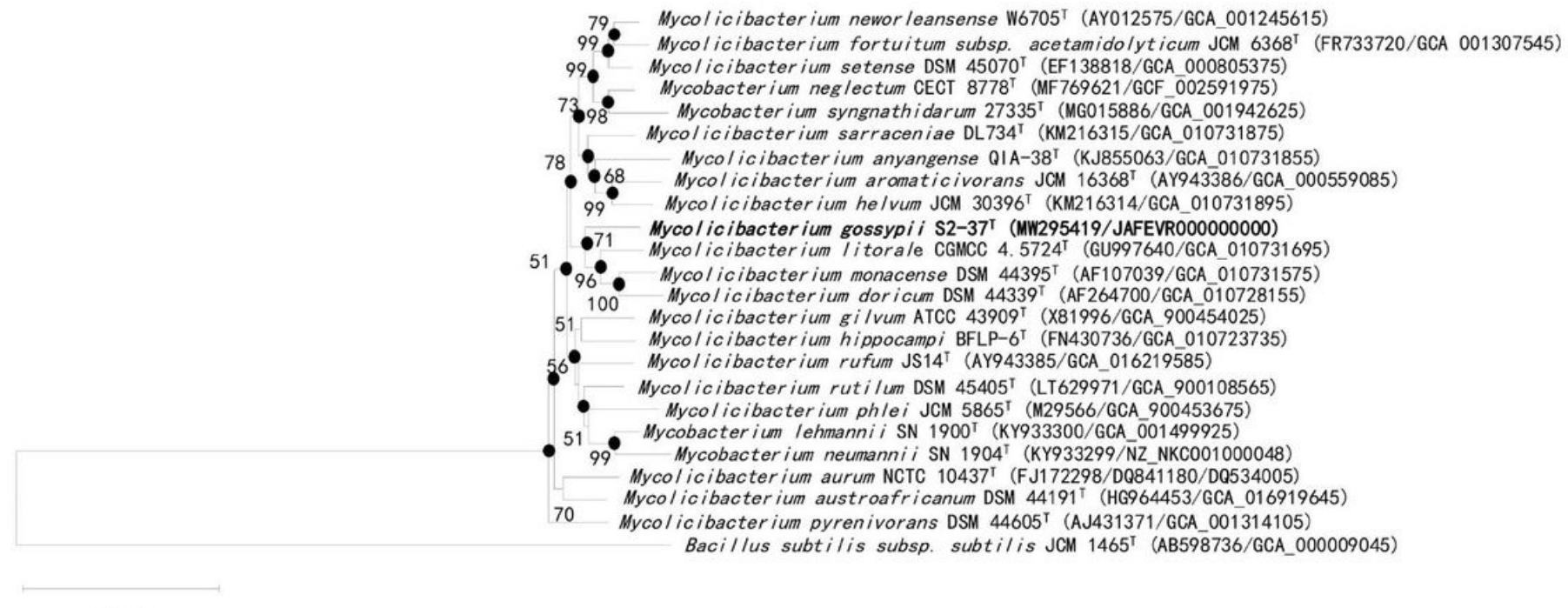

0.050

\section{Figure 1}

Phylogenetic trees reconstructed by the neighbour-joining method based on 16S rRNA (a) and multilocus gene (16S rRNA, hsp65 and rpoB) (b) sequences, which show the phylogenetic relationships between strain S2-37T and its closely related species. Bootstrap percentages (based on 1000 replications) above $50 \%$ are shown at the nodes. The GenBank accession numbers for the 16S rRNA gene and genomic sequences are shown in parentheses. Bacillus subtilis subsp. subtilis JCM $1465 \mathrm{~T}$ was employed as the 
outgroup. Filled circles indicate that the corresponding nodes are also recovered in trees reconstructed by the ML and MP algorithms. Bar, 0.02 (a) and 0.05 (b) substitutions per nucleotide position.

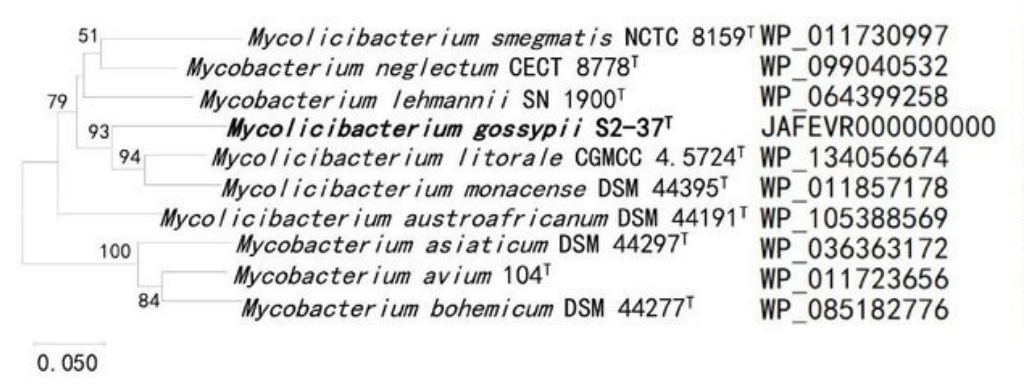

189

GHRD I GLLTMRLGRDWPHGDPRPALADPERVLSPHFHVQRER GHRQIGLLTMRLDRDWPHG-AKPALADPERVKTPHFHVQRER GHRE I GLLTMRLGRDRPKGGAGPTVADPQRLQTPHFHVQRER GHRE I GILTMRLGIDRPDGDPSPRI ADPERLARPRFHVQRER GHRE I GLLTMRLGLERPDGS-RPTVADPERLRTPHFHVQRER GHRDIGLLTMRLGLDRPDGDPRPAVAHPDRLRTPHFHVQRER GHRE I GLLTMRLGRDRPHGGSTPVLADPERLRTPHFHVQGER GHRE I GLLTMRLGDDRRM-----GLVDPERLRSPTFDVQRER GHRE I GLLTMRLGRDRRQ-----GLVDAERLRSPAFDVQRER GHRE I GLLTMRLGRDRRQ-----GLADAERLQSPAFDVQRER

\section{Figure 2}

The phylogenetic tree displayed in the left column is reconstructed by the neighbour囚joining method based on the whole sequences of Lacl family transcriptional regulator from tested members of the genus Mycocilibacterium and Mycobacterium, conserved region alignment of which is displayed in the right colume. Sequence information for additional CSIs is shown in Supplementary Figure 5. 


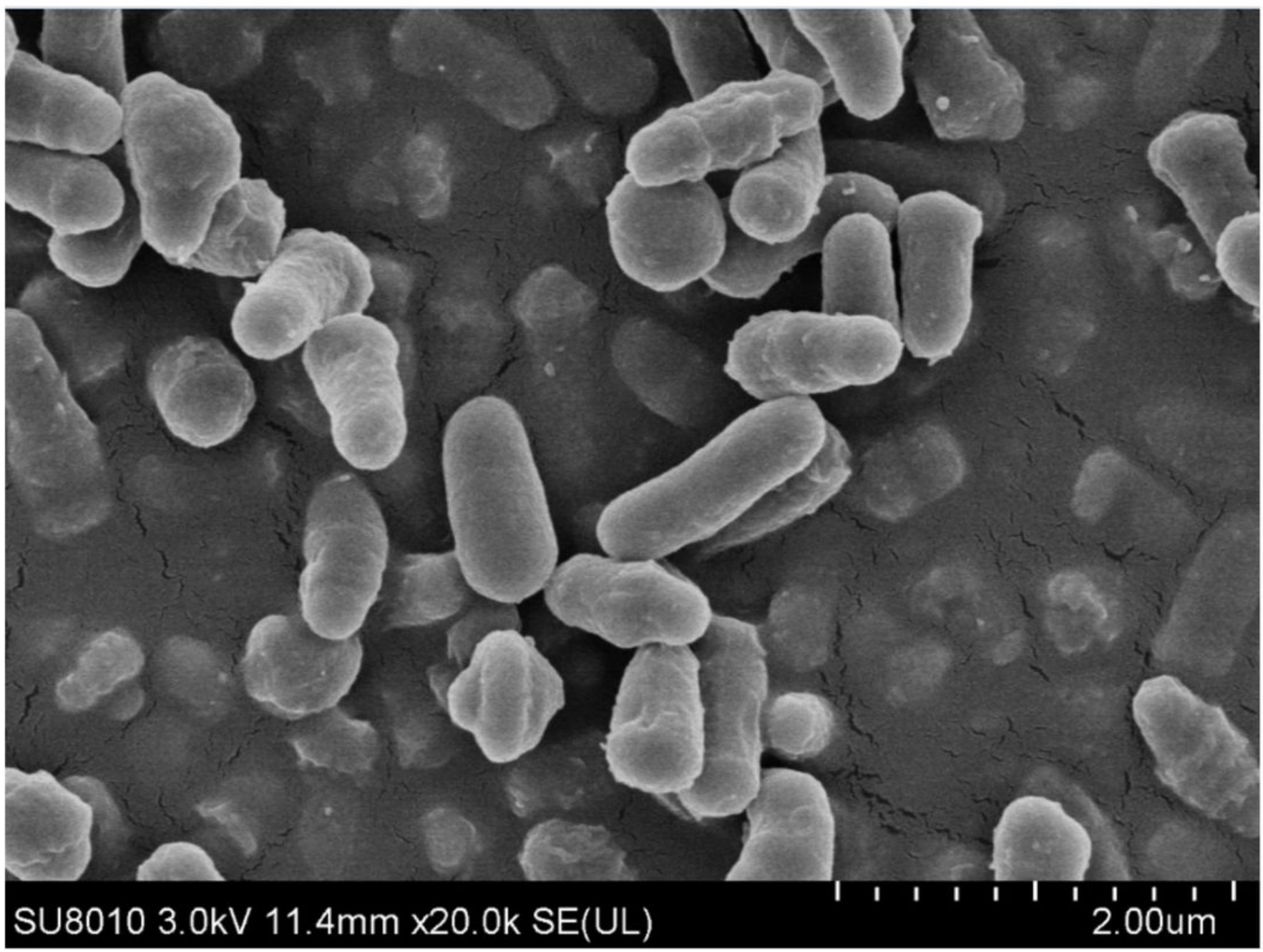

\section{Figure 3}

Scanning electron micrograph exhibiting cell morphology of strain S2-37T . The cells used for investigation were cultured on Bennett's agar at $30^{\circ} \mathrm{C}$ for $4 \mathrm{~d}$. Magnification, $\times 20.0 \mathrm{k}$. Scale bar, $2.0 \mu \mathrm{m}$

\section{Supplementary Files}

This is a list of supplementary files associated with this preprint. Click to download.

- Supplementaryfile1.pdf

- Supplementaryfile2.xls 